\title{
Mössbauer Study of Mechanosynthesized and Thermally Treated Co-Fe-Ni Alloys
}

\author{
T. Pikula ${ }^{a, *}$, D. Oleszak ${ }^{b}$, M. PȩKala ${ }^{c}$, M. Mazurek $^{a}$, \\ J.K. ŻURAWICZ ${ }^{a}$ AND E. JARTYCH ${ }^{a}$ \\ ${ }^{a}$ Department of Experimental Physics, Institute of Physics \\ Technical University of Lublin, Nadbystrzycka 38, 20-618 Lublin, Poland \\ ${ }^{b}$ Faculty of Materials Science and Engineering \\ Warsaw University of Technology \\ Wołoska 141, 02-507 Warsaw, Poland \\ ${ }^{c}$ Department of Chemistry, University of Warsaw \\ al. Żwirki i Wigury 101, 02-089 Warsaw, Poland

\begin{abstract}
Mechanical alloying was used to prepare $\mathrm{Co}_{40} \mathrm{Fe}_{60}, \mathrm{Co}_{60} \mathrm{Fe}_{35} \mathrm{Ni}_{5}$, $\mathrm{Co}_{40} \mathrm{Fe}_{45} \mathrm{Ni}_{15}$, and $\mathrm{Co}_{40} \mathrm{Fe}_{35} \mathrm{Ni}_{25}$ alloys from the elemental powders. As $\mathrm{X}$-ray diffraction studies proved the final products of milling were the solid solutions with bcc or fcc lattice and the average grain size between 20 and $50 \mathrm{~nm}$. After heating of the alloys up to $993 \mathrm{~K}$, the mixtures of two solid solutions with bcc and fcc lattices were formed in the case of $\mathrm{Co}-\mathrm{Fe}-\mathrm{Ni}$ alloys. Thermal treatment did not influence the type of the lattice of $\mathrm{Co}_{40} \mathrm{Fe}_{60}$ alloy. The Mössbauer spectroscopy revealed hyperfine magnetic field distribution ranged from 33 to $38 \mathrm{~T}$ for $\mathrm{Co}_{40} \mathrm{Fe}_{60}$ alloy and from 30 to $37 \mathrm{~T}$ for $\mathrm{Co}-\mathrm{Fe}-$ $\mathrm{Ni}$ alloys. In the case of two-phase alloys, distributions were decomposed into two simple Gaussian functions using the numerical fitting. Magnetic measurements allowed to determine the effective magnetic moments and the Curie temperatures of the obtained alloys.
\end{abstract}

PACS numbers: 81.20.Ev, 75.50.Kj, 76.80.+y, 75.60.Ej

\section{Introduction}

It is known that $\mathrm{Co}-\mathrm{Fe}-\mathrm{Ni}$ ternary alloys, especially as thin layers, are interesting materials because of their good soft magnetic properties causing the application of these alloys as write head core materials in hard-disk drives [1-3]. Recently, we have suggested the mechanical alloying (MA) as the potential technology of production of $\mathrm{Co}-\mathrm{Fe}-\mathrm{Ni}$ alloys as soft magnetic powders. Such alloys

*corresponding author; e-mail: t.pikula@pollub.pl 
reach saturation magnetization of the order of 1.6-1.8 T and coercive field about 1193-5331 $\mathrm{A} \mathrm{m}^{-1}[4,5]$. The values of the coercive field reported by us for mechanically synthesized $\mathrm{Co}-\mathrm{Fe}-\mathrm{Ni}$ alloys are comparable with those for nanocrystalline Fe-based alloys, for example FeCoZr or FeCuNbSiB, and they are placed on the left side of the well known Herzer dependence of coercivity on grain size for various soft magnetic metallic alloys (see Fig. 1) [6].

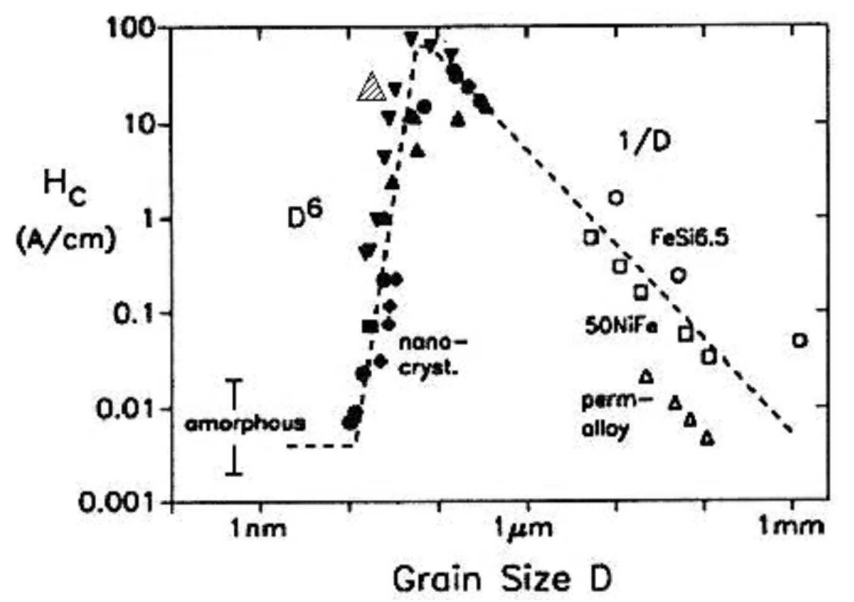

Fig. 1. Coercive field versus grain size for soft magnetic materials: $\mathbf{\Delta}-$ FeNbSiB, - - FeCuNbSiB, - FeCuVSiB, $-\mathrm{FeZrB}, \boldsymbol{\nabla}$ - FeCoZr (Ref. [6] and references therein); slashed triangle - region of our results for $\mathrm{Co}-\mathrm{Fe}-\mathrm{Ni}$ alloys [4, 5].

This work follows our systematic investigations of the mechanically synthesized $\mathrm{Co}-\mathrm{Fe}-\mathrm{Ni}$ alloys subjected to thermal treatment, subsequently. The chemical compositions were chosen on the basis of the phase diagram reported for the Co-rich $\mathrm{Co}-\mathrm{Fe}-\mathrm{Ni}$ bulk alloys obtained by melting [3] and the diagram showing regions of composition with high saturation magnetic flux density for these alloys (Ref. [1] and references therein). Structural properties and hyperfine interactions of the alloys after MA process as well as after thermal treatment were characterized on the basis of X-ray diffraction (XRD) and Mössbauer spectroscopy (MS), respectively. Moreover, the macroscopic magnetic properties of the alloys were determined from the magnetic measurements. In our previous studies we have proved that MA is a method providing $\mathrm{Co}-\mathrm{Fe}-\mathrm{Ni}$ alloys, which are in the nonequilibrium state [7]. Thermal treatment of the mechanosynthesized alloys have caused the structural changes, i.e. an increase in the grain size accompanied with a decrease in the level of internal strains, the change of the type of the crystalline lattice or the decomposition of the alloy into the mixture of two solid solutions with bcc and fcc lattice, respectively [7]. The aim of this work was to estimate the contributions of the suitable solid solutions in the decomposed alloys on the basis of the hyperfine magnetic field distributions. 


\section{Experiment}

Elemental powders of $\mathrm{Co}, \mathrm{Fe}$ and $\mathrm{Ni}$ with a purity of $99.9 \%$ were subjected to MA process to obtain $\mathrm{Co}_{40} \mathrm{Fe}_{60}, \mathrm{Co}_{60} \mathrm{Fe}_{35} \mathrm{Ni}_{5}, \mathrm{Co}_{40} \mathrm{Fe}_{45} \mathrm{Ni}_{15}$, and $\mathrm{Co}_{40} \mathrm{Fe}_{35} \mathrm{Ni}_{25}$ alloys. The high-energy Fritsch P5 planetary ball mill with stainless-steel vial and balls was used. The milling was performed under an argon atmosphere. Mechanical alloying processes were conducted up to $100 \mathrm{~h}$.

XRD measurements were performed using a Philips PW 1830 diffractometer working in a continuous scanning mode with $\mathrm{Cu} K_{\alpha}$ radiation. On the basis of the XRD patterns, the average grain sizes, $D$, and the mean level of internal strains, $\varepsilon$, were determined using the Williamson-Hall approach [8]. The lattice constants were determined from the shift of the diffraction lines.

MS studies were carried out at room temperature in standard transmission geometry using a source of ${ }^{57} \mathrm{Co}$ in a rhodium or a chromium matrix.

Temperature dependences of magnetization were measured on a Faraday balance up to $1100 \mathrm{~K}$ in magnetic field up to $1.5 \mathrm{~T}$ with the relative accuracy better than $1 \%$. The temperature was stabilized within $\pm 0.5 \mathrm{~K}$ and the heating rate was up to $4 \mathrm{~K}$ per min.

Thermal treatment of the mechanosynthesized $\mathrm{Co}_{40} \mathrm{Fe}_{60}, \mathrm{Co}_{60} \mathrm{Fe}_{35} \mathrm{Ni}_{5}$, $\mathrm{Co}_{40} \mathrm{Fe}_{45} \mathrm{Ni}_{15}$, and $\mathrm{Co}_{40} \mathrm{Fe}_{35} \mathrm{Ni}_{25}$ alloys was performed in two ways: (1) heating from the room temperature up to $993 \mathrm{~K}$ in a calorimeter under an argon atmosphere with the rate of $20 \mathrm{~K}$ per min and (2) isothermal annealing in a furnace at $1173 \mathrm{~K}$ for $1 \mathrm{~h}$ in vacuum.

\section{Results and discussion}

As XRD and MS measurements proved, the alloys started to form after $5 \mathrm{~h}$ of milling. Figure 2 presents the XRD patterns of the final product of milling (after $100 \mathrm{~h} \mathrm{MA}$ ) and patterns for the heated and annealed samples. Detailed analysis of XRD patterns allowed to state that during MA process of $\mathrm{Co}_{40} \mathrm{Fe}_{60}$, $\mathrm{Co}_{60} \mathrm{Fe}_{35} \mathrm{Ni}_{5}$, and $\mathrm{Co}_{40} \mathrm{Fe}_{45} \mathrm{Ni}_{15}$ alloys, the disordered solid solutions with bcc lattice were formed. In the case of $\mathrm{Co}_{40} \mathrm{Fe}_{35} \mathrm{Ni}_{25}$ alloy, the disordered solid solution with fcc lattice was obtained in MA process. These results agree with the phase diagram for the bulk Co-rich melted $\mathrm{Co}-\mathrm{Fe}-\mathrm{Ni}$ alloys reported in [3]. It may be noted that both thermal processes did not change the type of the crystalline lattice in the case of $\mathrm{Co}_{40} \mathrm{Fe}_{60}$ alloy (Fig. 2a). The $\mathrm{Co}_{60} \mathrm{Fe}_{35} \mathrm{Ni}_{5}$ and $\mathrm{Co}_{40} \mathrm{Fe}_{35} \mathrm{Ni}_{25}$ alloys heated up to $993 \mathrm{~K}$ were decomposed into the mixture of bcc and fcc phases as seen in Fig. $2 \mathrm{~b}$ and $\mathrm{c}$ (also in the case of $\mathrm{Co}_{40} \mathrm{Fe}_{45} \mathrm{Ni}_{15}$ alloy, not shown in Fig. 2). Annealing of the alloys at elevated temperature, $1173 \mathrm{~K}$, resulted in the formation of the mixture of two solid solutions in the case of $\mathrm{Co}_{60} \mathrm{Fe}_{35} \mathrm{Ni}_{5}$ and $\mathrm{Co}_{40} \mathrm{Fe}_{45} \mathrm{Ni}_{15}$ alloys, while the fcc phase was stable in the case of $\mathrm{Co}_{40} \mathrm{Fe}_{35} \mathrm{Ni}_{25}$ alloy (Fig. 2c). All the structural parameters for the investigated alloys after MA process as well as after thermal treatment are listed in Table I. 

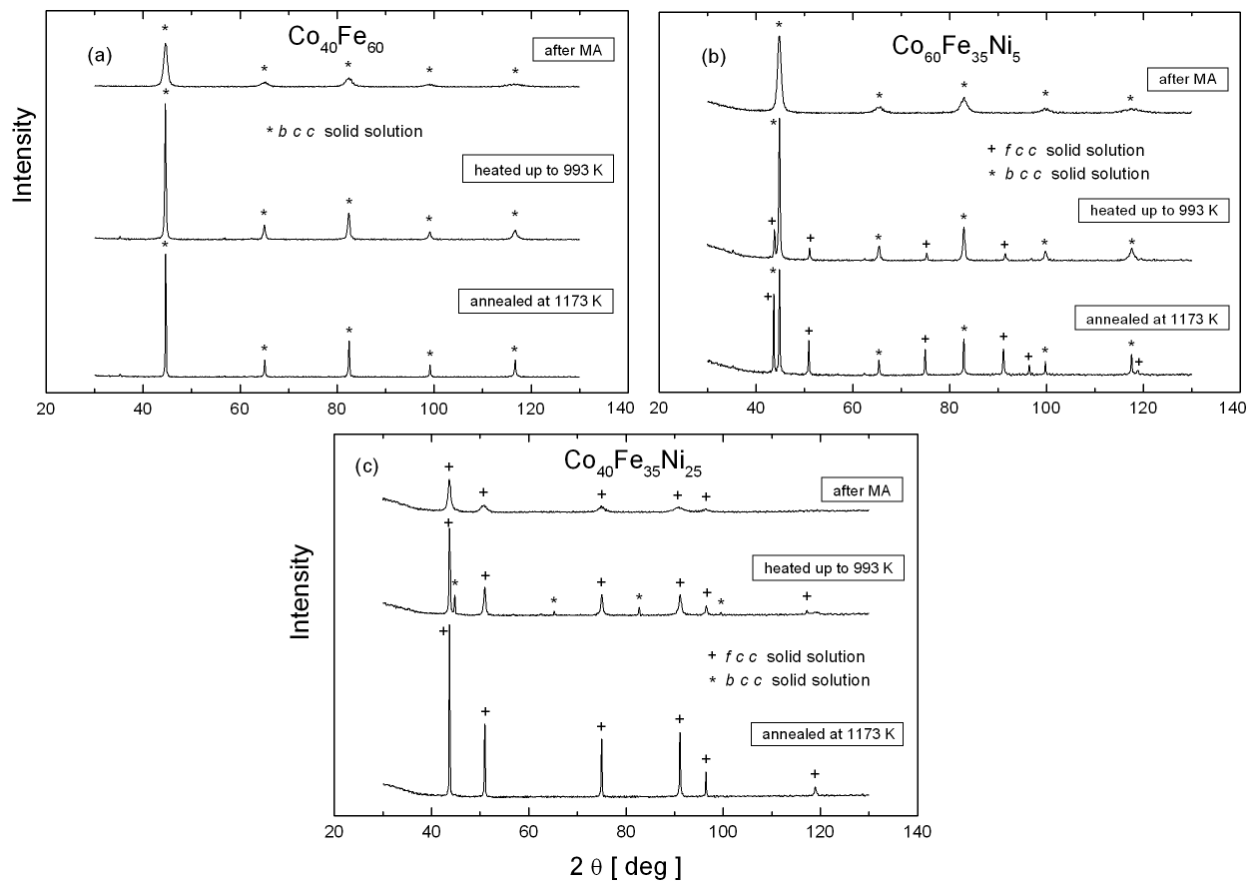

Fig. 2. XRD patterns of (a) $\mathrm{Co}_{40} \mathrm{Fe}_{60}$, (b) $\mathrm{Co}_{60} \mathrm{Fe}_{35} \mathrm{Ni}_{5}$, and (c) $\mathrm{Co}_{40} \mathrm{Fe}_{35} \mathrm{Ni}_{25}$ alloys.

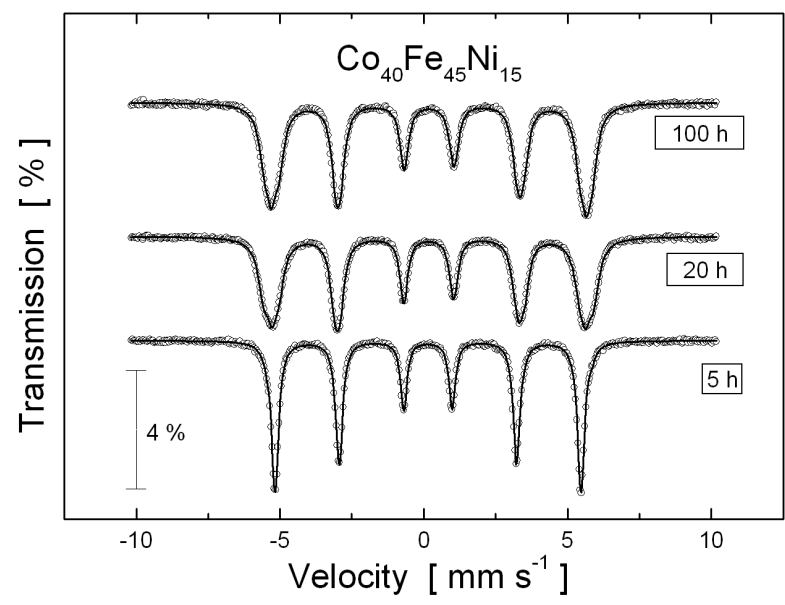

Fig. 3. Room-temperature Mössbauer spectra of $\mathrm{Co}_{40} \mathrm{Fe}_{45} \mathrm{Ni}_{15}$ alloy after various milling times.

All Mössbauer spectra registered for the samples after the particular milling times and after thermal treatment are six-like patterns. Figure 3 presents an example of the MS spectra for various milling times for $\mathrm{Co}_{40} \mathrm{Fe}_{45} \mathrm{Ni}_{15}$ alloy. Since the alloys are disordered solid solutions (it means that the Co, Fe and Ni atoms 
TABLE I

Structural data for mechanically synthesized $\mathrm{Co}_{40} \mathrm{Fe}_{60}$ and $\mathrm{Co}-$ $\mathrm{Fe}-\mathrm{Ni}$ alloys before and after heat treatment; $a$ - lattice constant, $D$ - average grain size, $\varepsilon$ - mean level of internal strains (uncertainty of the parameters are given in parentheses for the last significant number).

\begin{tabular}{c|c|c|c|c}
\hline \hline Alloy & Lattice & $\begin{array}{c}a \\
{[\mathrm{~nm}]}\end{array}$ & $\begin{array}{c}D \\
{[\mathrm{~nm}]}\end{array}$ & $\begin{array}{c}\varepsilon \\
{[\%]}\end{array}$ \\
\hline $\mathrm{Co}_{40} \mathrm{Fe}_{60}$ after MA & bcc & $0.2865(1)$ & $50(20)$ & $0.8(4)$ \\
heated up to $993 \mathrm{~K}$ & bcc & $0.2862(1)$ & $70(20)$ & $0.15(5)$ \\
annealed at $1173 \mathrm{~K}$ & bcc & $0.2862(1)$ & $>100$ & $\approx 0$ \\
\hline $\mathrm{Co}_{60} \mathrm{Fe}_{35} \mathrm{Ni}_{5}$ after MA & bcc & $0.2846(1)$ & $40(20)$ & $0.8(4)$ \\
heated up to $993 \mathrm{~K}$ & bcc & $0.2849(1)$ & $40(20)$ & $0.10(5)$ \\
& fcc & $0.3564(3)$ & $60(10)$ & $0.10(2)$ \\
annealed at $1173 \mathrm{~K}$ & bcc & $0.2848(1)$ & $>100$ & $\approx 0$ \\
& fcc & $0.3575(1)$ & $70(30)$ & $\approx 0$ \\
\hline $\mathrm{Co}_{40} \mathrm{Fe}_{45} \mathrm{Ni}_{15}$ after MA & bcc & $0.2852(1)$ & $20(10)$ & $0.7(5)$ \\
heated up to $993 \mathrm{~K}$ & bcc & $0.2857(1)$ & $70(30)$ & $0.1(1)$ \\
& fcc & $0.3578(1)$ & $55(25)$ & $\approx 0$ \\
annealed at $1173 \mathrm{~K}$ & bcc & $0.2859(1)$ & $30(15)$ & $\approx 0$ \\
& fcc & $0.3590(1)$ & $90(30)$ & $\approx 0$ \\
\hline $\mathrm{Co}_{40} \mathrm{Fe}_{35} \mathrm{Ni}_{25}$ after MA & fcc & $0.3577(8)$ & $20(15)$ & $0.6(5)$ \\
heated up to $993 \mathrm{~K}$ & bcc & $0.2852(1)$ & $50(10)$ & $\approx 0$ \\
& fcc & $0.3575(1)$ & $35(15)$ & $\approx 0$ \\
annealed at $1173 \mathrm{~K}$ & fcc & $0.3575(2)$ & $70(30)$ & $\approx 0$
\end{tabular}

occupy the lattice sites randomly), the Mössbauer spectra were fitted using the hyperfine magnetic field (HMF) distribution. The distributions were obtained for the samples after particular milling times and after heat treatment. It was noted that after $5 \mathrm{~h}$ of MA process besides the component originating from iron $\left(B_{\mathrm{hf}} \approx\right.$ $33 \mathrm{~T}$ ), an additional component with higher field (above $35 \mathrm{~T}$ ) appeared, which proved the formation of $\mathrm{Co}-\mathrm{Fe}$ or $\mathrm{Co}-\mathrm{Fe}-\mathrm{Ni}$ alloys. The distributions obtained for the samples milled for longer times were broadened and smoothened. Figure 4 presents the HMF distributions for $\mathrm{Co}_{60} \mathrm{Fe}_{35} \mathrm{Ni}_{5}, \mathrm{Co}_{40} \mathrm{Fe}_{45} \mathrm{Ni}_{15}$, and $\mathrm{Co}_{40} \mathrm{Fe}_{35} \mathrm{Ni}_{25}$ alloys after MA process as well as after heating or annealing. From the HMF distributions, the average values of HMF and the dispersions of the distributions were determined and they are listed in Table II. It may be added that in the case of $\mathrm{Co}_{40} \mathrm{Fe}_{60}$ alloy the values of hyperfine magnetic fields were ranged from 33 to $38 \mathrm{~T}$, while for the $\mathrm{Co}-\mathrm{Fe}-\mathrm{Ni}$ alloys from 30 to $37 \mathrm{~T}$. Moreover, the shape of HMF distributions obtained for single-phase alloys was quite regular and similar to a simple Gaussian function. 


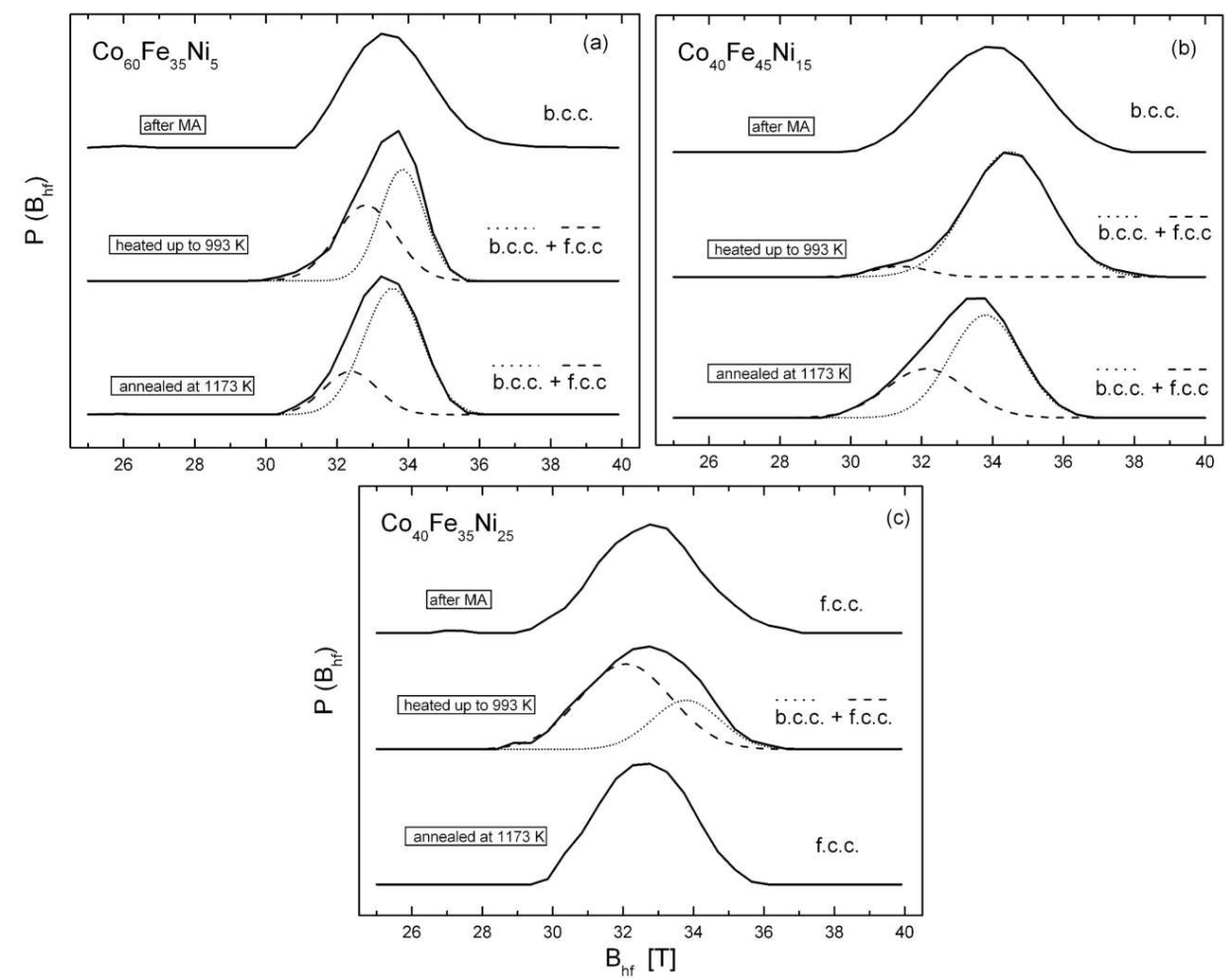

Fig. 4. Hyperfine magnetic field distributions of (a) $\mathrm{Co}_{60} \mathrm{Fe}_{35} \mathrm{Ni}_{5}$, (b) $\mathrm{Co}_{40} \mathrm{Fe}_{45} \mathrm{Ni}_{15}$, and (c) $\mathrm{Co}_{40} \mathrm{Fe}_{35} \mathrm{Ni}_{25}$ alloys after MA process and after thermal treatment; $P\left(B_{\mathrm{hf}}\right)-$ probability in arbitrary units.

As mentioned, in the case of all heated $\mathrm{Co}-\mathrm{Fe}-\mathrm{Ni}$ alloys, the annealed $\mathrm{Co}_{60} \mathrm{Fe}_{35} \mathrm{Ni}_{5}$ and $\mathrm{Co}_{40} \mathrm{Fe}_{45} \mathrm{Ni}_{15}$ alloys, the thermal processes have caused the formation of the mixture of bcc and fcc solid solutions. The suitable HMF distributions were numerically decomposed into two parts which were attributed to individual phases. In the procedure, the experimental HMF distributions were fitted using two Gaussian functions. Such starting parameters, as half width of the Gaussian curve, its amplitude, center position were chosen on the basis of properties of distributions obtained for the single-phase samples. The program allowed to estimate the area of the individual Gaussian component ( $A$ in \%) assuming that the total area of the experimental HMF distribution is $100 \%$. Moreover, the average value of the hyperfine magnetic field, $\langle B\rangle$, for each component was calculated. Both values, $A$ and $\langle B\rangle$ are listed in Table II.

Results of magnetic measurements are presented in Fig. 5. From the magnetization curves the room-temperature magnetization, $\sigma_{\mathrm{RT}}$ and the effective magnetic moment per formula unit, $\mu_{\text {eff }}$, were determined. The Curie temperature, $T_{\mathrm{C}}$, was estimated by extrapolation of the high temperature part of the magneti- 
TABLE II

Hyperfine magnetic fields for mechanically synthesized $\mathrm{Co}_{40} \mathrm{Fe}_{60}$ and $\mathrm{Co}-\mathrm{Fe}-\mathrm{Ni}$ alloys before and after heat treatment; $\left\langle B_{\mathrm{hf}}\right\rangle-$ average hyperfine magnetic field, $\sigma_{\mathrm{B}}$ - dispersion of the HMF distribution, $A$ - area of the component, $\langle B\rangle$ - average hyperfine magnetic field for component.

\begin{tabular}{|c|c|c|c|c|c|c|c|}
\hline \multirow[b]{2}{*}{ Alloy } & \multirow[b]{2}{*}{ State } & \multirow[b]{2}{*}{$\begin{array}{c}\left\langle B_{\mathrm{hf}}\right\rangle \\
{[\mathrm{T}]}\end{array}$} & \multirow[b]{2}{*}{$\begin{array}{l}\sigma_{\mathrm{B}} \\
{[\mathrm{T}]}\end{array}$} & \multicolumn{4}{|c|}{ Phase } \\
\hline & & & & $\begin{array}{c}\text { fcc } \\
A \\
{[\%]}\end{array}$ & $\begin{array}{l}\langle B\rangle \\
{[\mathrm{T}]}\end{array}$ & $\begin{array}{c}\text { bcc } \\
A \\
{[\%]}\end{array}$ & $\begin{array}{l}\langle B\rangle \\
{[\mathrm{T}]}\end{array}$ \\
\hline \multirow{3}{*}{$\mathrm{Co}_{40} \mathrm{Fe}_{60}$} & after MA & 35.45 & 1.14 & - & - & 100 & - \\
\hline & heated up & 35.15 & 0.90 & - & - & 100 & - \\
\hline & annealed & 34.95 & 0.81 & - & - & 100 & - \\
\hline \multirow{3}{*}{$\mathrm{Co}_{60} \mathrm{Fe}_{35} \mathrm{Ni}_{5}$} & after MA & 33.50 & 1.07 & - & - & 100 & - \\
\hline & heated up & 33.30 & 0.89 & 48 & 32.8 & 52 & 33.8 \\
\hline & annealed & 33.25 & 0.91 & 24 & 32.4 & 76 & 33.6 \\
\hline \multirow{3}{*}{$\mathrm{Co}_{40} \mathrm{Fe}_{45} \mathrm{Ni}_{15}$} & after MA & 33.88 & 1.37 & - & - & 100 & - \\
\hline & heated up & 34.35 & 1.33 & 6 & 31.4 & 94 & 34.5 \\
\hline & annealed & 33.22 & 1.25 & 35 & 32.1 & 65 & 33.8 \\
\hline \multirow{3}{*}{$\mathrm{Co}_{40} \mathrm{Fe}_{35} \mathrm{Ni}_{25}$} & after MA & 32.75 & 1.39 & 100 & - & - & - \\
\hline & heated up & 32.60 & 1.41 & 70 & 32.0 & 30 & 33.7 \\
\hline & annealed & 32.61 & 1.17 & 100 & - & - & - \\
\hline
\end{tabular}

zation curve. The values of $\sigma_{\mathrm{RT}}, \mu_{\mathrm{eff}}$ and $T_{\mathrm{C}}$ are presented in Table III. It may be noted that thermal treatment had no significant influence on the Curie temperature of the alloys, while the structural changes which occurred during heating or annealing caused a decrease or an increase in the values of the room-temperature magnetization as well as the effective magnetic moments. The obtained magnitudes of $\mu_{\text {eff }}$ lie between $2.41 \mu_{\mathrm{B}}$ for bulk $\mathrm{Co}_{50} \mathrm{Fe}_{50}$ alloy and $1.19 \mu_{\mathrm{B}}$ for $\mathrm{Co}_{50} \mathrm{Ni}_{50}$ alloy [9]. The Curie temperatures for mechanically synthesized $\mathrm{Co}-\mathrm{Fe}-\mathrm{Ni}$ alloys are significantly lower than $T_{\mathrm{C}}=1393 \mathrm{~K}$ for pure cobalt or than $T_{\mathrm{C}}$ for bulk Co-Fe alloys $\left(1253 \mathrm{~K}\right.$ for $\mathrm{Co}_{40} \mathrm{Fe}_{60}$ and $1213 \mathrm{~K}$ for $\left.\mathrm{Co}_{60} \mathrm{Fe}_{40}\right)$ and $\mathrm{Co}-\mathrm{Ni}$ alloys (1198 $\mathrm{K}$ for $\mathrm{Co}_{60} \mathrm{Ni}_{40}$ ) [10]. The reduced Curie temperature of the investigated $\mathrm{Co}-\mathrm{Fe}-\mathrm{Ni}$ alloys after MA may be caused by the relatively high value of the lattice strains as well as by the large amount of atoms located in strongly disordered grain boundaries. 

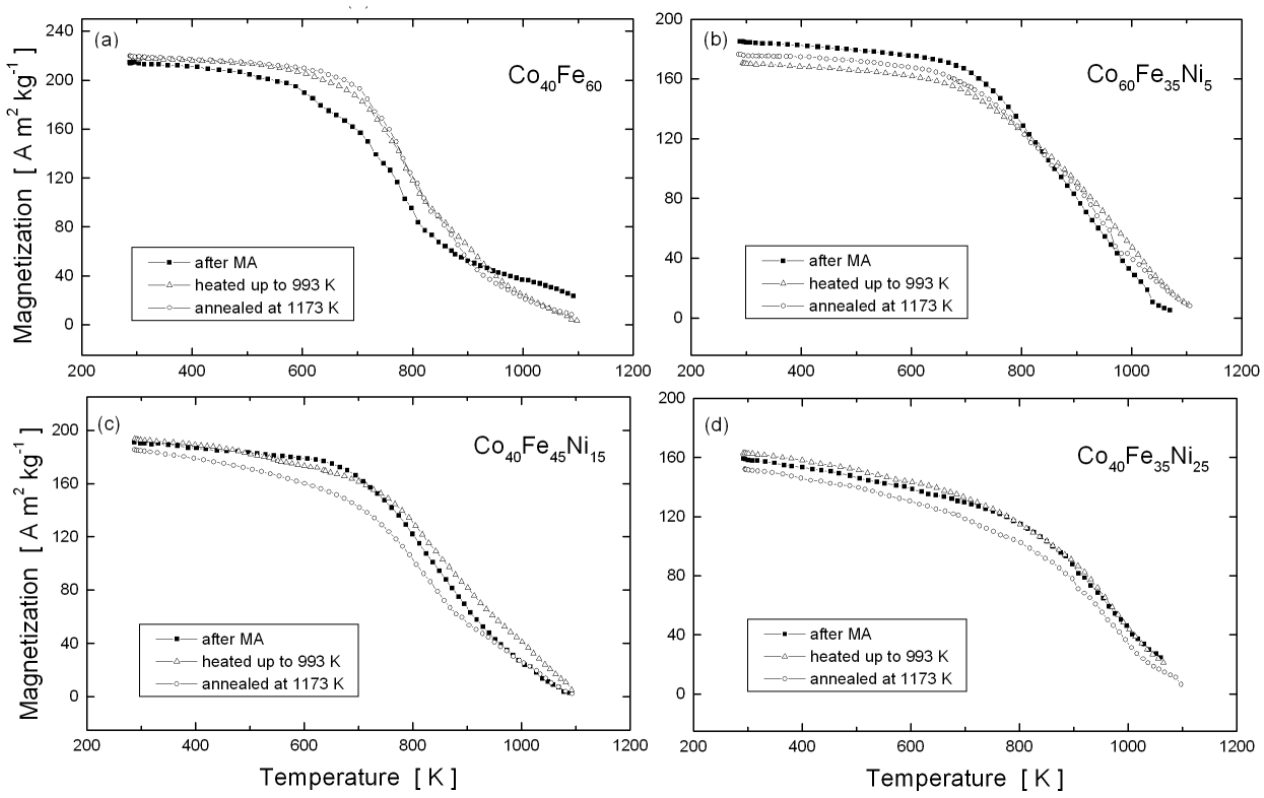

Fig. 5. Magnetization as a function of temperature of the mechanosynthesized $\mathrm{Co}-\mathrm{Fe}-\mathrm{Ni}$ alloys before and after thermal treatment.

TABLE III

Magnetic data for mechanically synthesized $\mathrm{Co}_{40} \mathrm{Fe}_{60}$ and $\mathrm{Co}-\mathrm{Fe}-\mathrm{Ni}$ alloys before and after heat treatment; $\sigma_{\mathrm{RT}}$ - room-temperature magnetization, $\mu_{\mathrm{eff}}$ - effective magnetic moment per formula unit, $T_{\mathrm{C}}$ - Curie temperature.

\begin{tabular}{c|c|c|c}
\hline \hline Composition & $\begin{array}{c}\sigma_{\mathrm{RT}} \\
{\left[\mathrm{A} \mathrm{m}^{2} \mathrm{~kg}^{-1}\right]}\end{array}$ & $\begin{array}{c}\mu_{\mathrm{eff}} \\
{\left[\mu_{\mathrm{B}}\right]}\end{array}$ & $\begin{array}{c}T_{\mathrm{C}} \\
{[\mathrm{K}]}\end{array}$ \\
\hline $\mathrm{Co}_{40} \mathrm{Fe}_{60}$ after MA & 214.4 & 2.256 & 1150 \\
heated up to $993 \mathrm{~K}$ & 217.9 & 2.297 & 1100 \\
annealed at $1173 \mathrm{~K}$ & 219.1 & 2.315 & 1100 \\
\hline $\mathrm{Co}_{60} \mathrm{Fe}_{35} \mathrm{Ni}_{5}$ after MA & 184.8 & 1.915 & 1028 \\
heated up to $993 \mathrm{~K}$ & 170.4 & 1.765 & 1110 \\
annealed at $1173 \mathrm{~K}$ & 175.8 & 1.824 & 1110 \\
\hline $\mathrm{Co}_{40} \mathrm{Fe}_{45} \mathrm{Ni}_{15}$ after MA & 192.8 & 1.964 & 1100 \\
heated up to $993 \mathrm{~K}$ & 192.9 & 1.989 & 1100 \\
annealed at $1173 \mathrm{~K}$ & 184.8 & 1.906 & 1100 \\
\hline $\mathrm{Co}_{40} \mathrm{Fe}_{35} \mathrm{Ni}_{25}$ after MA & 158.8 & 1.648 & 1130 \\
heated up to $993 \mathrm{~K}$ & 162.9 & 1.685 & 1130 \\
annealed at $1173 \mathrm{~K}$ & 152.1 & 1.573 & 1130
\end{tabular}




\section{Conclusions}

On the basis of the performed studies and our previous results it may be stated that $\mathrm{Co}-\mathrm{Fe}-\mathrm{Ni}$ alloys prepared by MA process are in the non-equilibrium state. An increase in the grain sizes and a decrease in the internal strains of alloys were observed after thermal treatment. Moreover, most of alloys decomposed into the mixture of two solid solutions. In the case of $\mathrm{Co}_{40} \mathrm{Fe}_{60}$ alloy the phase composition of the alloy was stable after heating or annealing.

Alloys were characterized by the relatively broad HMF distributions. Generally, the average values of HMF for bcc alloys are larger than those for fcc alloys by about 1-2 T. In the case of two-phase alloys, the bcc solid solution is a dominant phase in $\mathrm{Co}_{40} \mathrm{Fe}_{60}, \mathrm{Co}_{60} \mathrm{Fe}_{35} \mathrm{Ni}_{5}$ and $\mathrm{Co}_{40} \mathrm{Fe}_{45} \mathrm{Ni}_{15}$ alloys, while in $\mathrm{Co}_{40} \mathrm{Fe}_{35} \mathrm{Ni}_{25}$ alloy the fcc solid solution plays the main role.

Possible trends in macroscopic magnetic properties of the mechanosynthesized and thermally treated $\mathrm{Co}-\mathrm{Fe}-\mathrm{Ni}$ alloys as well as the dependences between the hyperfine magnetic fields and magnetic moments will be a subject of further investigations.

\section{References}

[1] T. Osaka, Electrochim. Acta 45, 3311 (2000).

[2] X. Liu, G. Zangari, L. Shen, J. Appl. Phys. 87, 5410 (2000).

[3] S.U. Jen, H.P. Chiang, C.M. Chung, M.N. Kao, J. Magn. Magn. Mater. 236, 312 (2001)

[4] E. Jartych, J.K. Żurawicz, D. Oleszak, M. Pȩkała, Hyperfine Interact. 168, 989 (2006).

[5] T. Pikula, D. Oleszak, M. Pȩkała, J.K. Żurawicz, E. Jartych, Rev. Adv. Mater. Sci. 18, 322 (2008).

[6] G. Herzer, J. Magn. Magn. Mater. 112, 258 (1992).

[7] T. Pikula, D. Oleszak, M. Pȩkała, E. Jartych, J. Magn. Magn. Mater. 320, 413 (2008).

[8] G.K. Williamson, W.H. Hall, Acta Metallurg. 1, 22 (1953).

[9] P. Soderlind, O. Eriksson, B. Johansson, R.C. Albers, A.M. Boring, Phys. Rev. B 45, 12911 (1992).

[10] T.B. Massalski, Binary Alloy Phase Diagrams, ASM, Metals Park, Ohio, USA 1990, p. 1187. 